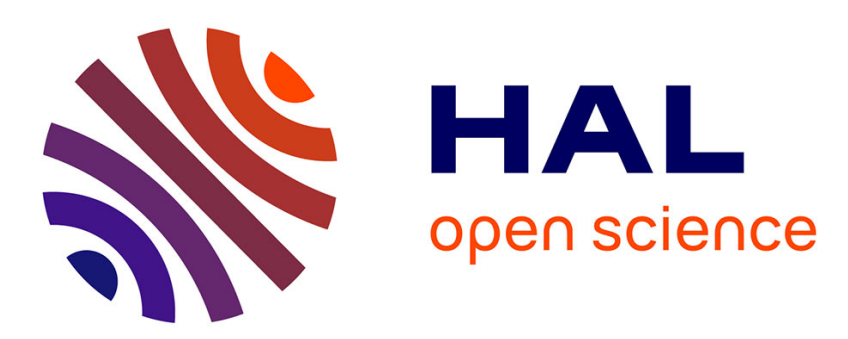

\title{
Price vs. weather shock hedging for cash crops: ex ante evaluation for cotton producers in Cameroon
}

\author{
Antoine Leblois, Philippe Quirion, Benjamin Sultan
}

\section{To cite this version:}

Antoine Leblois, Philippe Quirion, Benjamin Sultan. Price vs. weather shock hedging for cash crops: ex ante evaluation for cotton producers in Cameroon. Ecological Economics, 2014, pp.42. 10.1016/j.ecolecon.2014.02.021 . halshs-00967313

\section{HAL Id: halshs-00967313 https://shs.hal.science/halshs-00967313}

Submitted on 31 Mar 2014

HAL is a multi-disciplinary open access archive for the deposit and dissemination of scientific research documents, whether they are published or not. The documents may come from teaching and research institutions in France or abroad, or from public or private research centers.
L'archive ouverte pluridisciplinaire HAL, est destinée au dépôt et à la diffusion de documents scientifiques de niveau recherche, publiés ou non, émanant des établissements d'enseignement et de recherche français ou étrangers, des laboratoires publics ou privés. 


\title{
Price vs. weather shock hedging for cash crops: ex ante evaluation for cotton producers in Cameroon
}

\author{
Antoine Leblois*, Philippe Quirion ${ }^{\dagger}$ and Benjamin Sultan ${ }^{\ddagger}$
}

Janvier 2014

\begin{abstract}
In the Sudano-sahelian zone, which includes Northern Cameroon, the inter-annual variability of the rainy season is high and irrigation scarce. As a consequence, bad rainy seasons have a detrimental impact on crop yield. In this paper, we assess the risk mitigation capacity of weather index-based insurance for cotton farmers. We compare the ability of various indices, mainly based on daily rainfall, to increase the expected utility of a representative risk-averse farmer.

We first give a tractable definition of basis risk and use it to show that weather indexbased insurance is associated with a large basis risk, whatever the index considered. It has thus limited potential for income smoothing, a conclusion which is robust to the utility function. Second, in accordance with the existing agronomical literature we find that the length of the cotton growing cycle, in days, is the best performing index considered. Third, we show that using observed cotton sowing dates to define the length of the growing cycle significantly decreases the basis risk, compared to using simulated sowing dates. Finally we find that the gain of the weather-index based insurance is lower than that of hedging against cotton price fluctuations provided by the national cotton company. This casts doubt on the strategy of supporting weather-index insurances in cash crop sectors selling at international market prices without recommending any price stabilisation scheme.
\end{abstract}

Keywords: Weather, index-based insurance, cash crop, price risk.

JEL Codes: O12, Q12, Q18.

*CIRED (Centre International de Recherche sur l'Environnement et le Développement), leblois@centre-cired.fr.

†CIRED, LMD (Laboratoire de Météorologie Dynamique).

${ }_{\ddagger}^{\ddagger}$ LOCEAN (Laboratoire d'Océanographie et du Climat, Experimentation et Approches Numériques). 


\section{Introduction}

Traditional agricultural insurance suffers from an information asymmetry between the farmer (agent) and the insurer (principal), and thus requires costly damage assessment. Moral hazard issues indeed stem from the incentive for the farmer to reduce effort put into production when he knows that a bad yield will be compensated. An emerging alternative is insurance based on a weather index used as a proxy for crop yield (Berg et al., 2009). In such a scheme the farmer pays an insurance premium every year and receives an indemnity if the weather index falls below a determined level (the strike). Weather indexbased insurance (WII) does not suffer from the two shortcomings mentioned above: the weather index provides an objective, and relatively inexpensive, proxy of crop damages. However, its weakness is the basis risk that comes from the imperfect correlation between the weather index and the yields, or more precisely losses, of farmers contracting the insurance.

This paper therefore assesses WII contracts which aim at sheltering farmers against drought risk. Insurance indemnities are triggered by low values of the index supposed to explain yield variation. This kind of insurance makes it possible to pool risk across time and space in order to limit the impact of weather shocks on producer income.

A recent but prolific literature about WII in low income countries has analysed the impact of pilot programmes through ex post studies. The take up rates have been very low in those studies (in particular in two case studies in India: Giné et al., 2008 and Cole et al. 2013 and one in Malawi: Giné and Yang, 2009). These low take-up rates have been puzzling researchers (Karlan and Morduch, 2010). Several explanations have been proposed and tested in other recent ex-post studies: steep price elasticity; existing informal risk sharing networks (Karlan et al., 2012; Mobarak and Rosenzweig, 2013 and Cole et al., 2013); lack of trust or financial literacy (Hill et al., 2011; Cai et al., 2012 and Giné et al., 2012), compound risk aversion (Elabed et al., 2013) and ambiguity aversion (Bryan, 2010).

However, the possibility of the benefit of WII being too low given the basis risk and the costs of running the scheme has still not been ruled out and the question of the interest of such products for development still remains unsolved (Barnett et al., 2008 and 
Binswanger-Mkhize, 2012). Surprisingly there are few ex ante assessments of the benefits from, and basis risk of, WII in the long run. Ex ante estimations give a long run view and show anticipated gains in terms of consumption smoothing for farmers in ideal conditions. If these anticipated gains are low, they provide a simple explanation of the observed low take-up rate.

There are several studies looking at the ex ante benefit from WII in other locations and for other crops (Breustedt et al., 2008 in Kazakhstan; Vedenov and Barnett, 2004 in the US; Berg et al., 2009 in Burkina-Faso, De Bock et al, 2010, in Mali). These studies showed in particular that using a cross-validation technique is necessary to avoid overfitting, and that at best, these insurances can bring a significant benefit only for a few crops and locations among those analysed. The study with the closest target is de Bock et al. (2010) who studied the potential of index insurance for cotton in Mali but the match of annual rainfall and yield data was reduced to 3 districts due to data availability and to only one district because of a lack of correlation between the weather index and yield in the two others.

In this paper, we look at the potential benefit cotton farmers could gain from index insurance and at the design basis risk associated with various weather indices, by comparing it to area-yield insurance, i.e. an index perfectly correlated to observed cotton yield in the relevant location. We made this assessment using state-of-the-art techniques: we tested two utility functions, using several levels of risk aversion in the range of the results given by a field experiment and we used a cross-validation technique, controlling for over-fitting. To our knowledge, there is no similar work assessing the magnitude of basis risk of WII in the long run and for several localities using empirical data.

We use aggregated data, which prevents from studying the effect of idiosyncratic shocks that are known to be significant (Leblois et al., 2013), but we also compare areayield insurance to what can be considered as a benchmark risk management tool in the case of cash crops i.e. the hedging of intra-seasonal price fluctuations already offered by the national cotton company through a forward pricing mechanism. As in the other ex ante studies noted above, we do not consider the potential impact of insurance on farmers' behaviours (mainly risk taking and intensification) and on market access (mainly input and credit), limitations on which we will come back to later. 
The next section describes the cotton sector in Cameroon while the third is dedicated to describing the data and the methods. In the fourth section we present the results before concluding.

\section{Cotton sector in Cameroon}

\section{$2.1 \quad$ Recent trends}

According to Folefack et al. (2011), cotton is the major cash crop of Cameroon and represents the major source of income, monetary income in particular, for farmers (more than 200000 in 2010) of the two northern provinces: Nord and Extrême Nord. It is grown by smallholders with an average of about 0.7 hectares per farmer dedicated to cotton production in the whole area.

At the peak of production, in 2005, 350000 farmers cultivated 232000 ha while, between 2005 and 2010, the number of farmers and the area cultivated with cotton dropped by $40 \%$. Farmers abandoned cotton production after experiencing a dramatic reduction in their margin due mainly to an increase in fertilizer prices.

There are also significant weather-related risks. Cotton is indeed rainfed in almost all producing countries of sub Saharan African, and largely depends on rainfall availability. The impact of a potential modification of rainfall distribution during the season or the reduction of its length has recently been found to be of particular importance (cf. section 3.2 ) and could even be higher with an increased variability of rainfall (ICAC, 2007 and 2009) that may occur under global warming (Roudier et al., 2011). Moreover, farmers unable to reimburse their input credit at harvest ${ }^{1}$ are not allowed to take an input credit (for cotton but also for food crops) from the national cotton company during the next year. A situation of unpaid debt would thus be detrimental to cotton farmers in the long run (Folefack et al., 2011).

Lastly, the sector also faces other challenges: an isolation of the North of the country and a decline in soil fertility due to increasing land pressure.

\footnotetext{
${ }^{1}$ The standing crop is used as collateral and credit reimbursement is deducted from farmers' revenue when the national company purchases the cotton, cf. section 2.2 for further descriptions.
} 


\subsection{Purchasing price fixation, current hedging and input credit scheme}

In Cameroon, the cotton society (Sodecoton), like its Malian, Senegalese and Chadian counterparts, is still a national monopsony (Delpeuch and Leblois, 2013). It is thus the only agent to buy seed cotton from producers at a pan-seasonally and -territorially fixed price. It then gins the cotton and sells the fibre on international markets.

As already mentioned by Makdissi and Wodon (2004), price stabilisation has an impact on production decisions since it insures producers against intra-seasonal variations of the international cotton price by guaranteeing the announced price.

The cotton sector's institutional setting is also characterized by input provision. Costly inputs are indeed provided on credit by the national companies before sowing, ensuring a minimum input quality. Such inputs are made available in remote areas in spite of a substantial cash constraint that characterizes the sowing period corresponding to the end of the lean season: the so-called 'hunger gap'. Inputs are distributed at sowing (from May 20 onwards, depending on the latitude) and reimbursed at harvest. The amount of credit is deducted, at harvest, from the purchase of seed cotton.

\section{Data and methods}

\subsection{Area and data}

The cotton administration counts 9 regions divided into 38 administrative Sectors. Cotton farmers are grouped into producer groups (PGs), roughly corresponding to the village level. There were about 2000 active PGs in 2011, which represented an average of about 55 PGs per Sector (the spatial administrative unit used throughout this article).

Yield and profit per hectare are provided by the Sodecoton at the Sector level from 1977 to 2010. It is an aggregation of data from the producer groups' level used for the internal accounts of the national company. As the company is the only buyer and the only input provider in the country, it is an exhaustive database of the cotton producers in Cameroon. Area and production (used to calculate yield) and inputs excluding labor costs (used to calculate profits) are also very reliable because the company follows each growing 


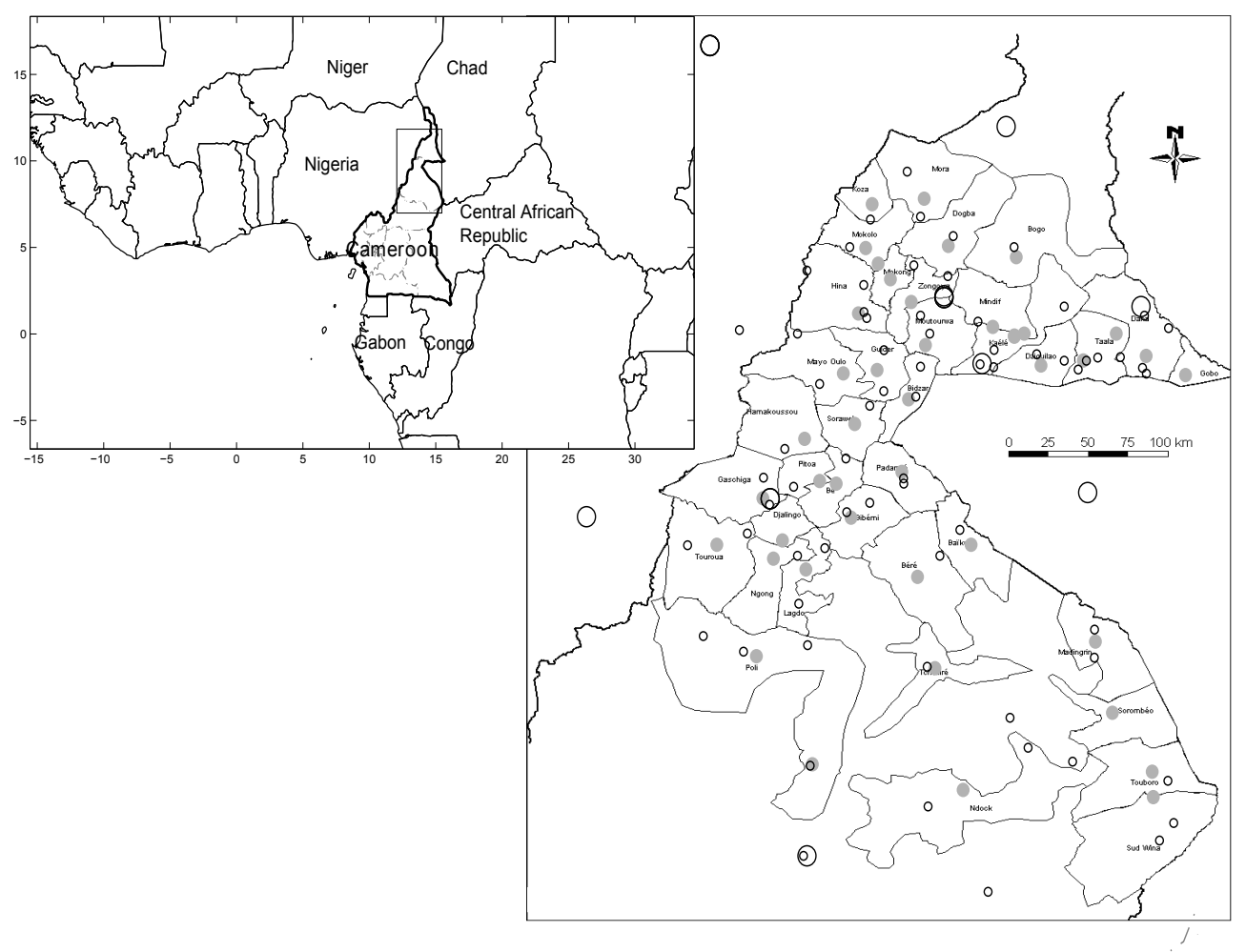

Figure 1: Network of weather stations (large circles) and rainfall stations (small circles) and Sodecoton's administrative zoning: the Sectors level. Sector locations (grey dots: average of GPS coordinates of every Sodecoton PG within the Sector) are at an average distance of $10 \mathrm{~km}$ and a maximum distance of $20 \mathrm{~km}$ of the nearest station. Sources: Sodecoton, IRD and GHCN (NOAA). 
campaign closely. Agronomic data are matched to a unique meteorological dataset built for this study. It includes daily rainfall and temperatures (minimum, maximum and average) coming from different sources $^{2}$, with at least one rainfall station per Sector (figure 1, a sector represents about 900 square kilometres).

We use ten IRD and Global Historical Climatology Network (GHCN) weather stations of the region: six in Cameroon and four in Chad and Nigeria ${ }^{3}$. Because of the low density of the network of weather stations, we interpolated temperature data for each Sector. We use a simple Inverse Distance Weighting interpolation technique ${ }^{4}$, each station being weighted by the inverse of its squared distance to the Sector considered. We apply a reduction proportional to 6.5 degrees Celsius $\left({ }^{\circ} \mathrm{C}\right)$ per 1000 meters altitude. The average annual cumulative rainfall over the whole producing zone is about $950 \mathrm{~mm}$ (table 1), hiding regional heterogeneities we explore in the next section.

Finally, in addition to rain and temperature data, we use the Normalized Difference Vegetation Index (NDVI) available for a 25 year period spanning from 1981 to 2006 at $8 \mathrm{~km}$ spatial resolution, which is directly related to green plant biomass ${ }^{5}$. Profit $\left(\Pi_{i, t}\right)$ observed at the sectoral level is the difference between the value of cotton sold and the value of purchased inputs.

$$
\Pi_{i, t}=P_{t} \times Y_{i, t}-C_{i, t}
$$

$i$ denotes the sector, $t$ is the time index with a yearly step, $P_{t}$ the annual cotton purchasing price for the whole cotton growing zone, $Y_{i, t}$ the yield in $\mathrm{kg}$ per hectare of one sector for a given year and $C_{i, t}$ the costs of inputs (fertilisers and pesticides) per hectare of one sector for a given year. Labour is not included since the vast majority of workers are self-employed. The unit used is the CFA franc, the parity of which is fixed at the exchange rate of $657.91 \mathrm{CFA}$ francs for 1 EUR. 1 USD thus represents approximately 500 CFA francs in 2013.

\footnotetext{
${ }^{2}$ Institut de la Recherche pour le Développement (IRD) and Sodecoton's high density network of rain gauges.

${ }^{3}$ National Oceanic and Atmospheric Administration (NOAA), available at: www7.ncdc.noaa.gov

${ }^{4}$ IDW method (Shepard 1968), with a power parameter of two.

5 The NOAA (GIMMS-AVRHH) remote sensing data are available online at: www.glcf.umd.edu/data/gimms), Pinzon et al. (2005).
} 
We will focus on the 1991-2004 sub-period, the summary statistics of which are similar to those of the whole period (cf. Appendix E for the indices studied) except for yields and profits which are significantly higher (table 1). We restricted the period under consideration for two reasons. First, the profit series suffered from a high attrition rate before 1991, with about one third of missing yield data (in comparison, only $18 \%$ is missing for the period between 1991 and 2010). Second, following our reference period, the collapse of the cotton sector since 2005 has caused cotton leaks, i.e. side-selling in borderland areas towards Nigeria, where prices are sometimes 3 times higher (Kaminsky et al., 2011). Production leaks and cotton inputs used for the benefit of food crops (as acknowledged by Folefack et al., 2011 from 2005 onwards, due to high input prices) could threaten the quality of the yield and profit data.

Inter-annual variations in Sodecoton purchasing prices and input costs contribute to variations in cotton profits throughout the period. We however do not take such variations into account since the inter-annual variations of input and cotton prices are considered in crop choice along with acreage and input use decisions. Hence, estimating the cost of these inter-annual variations would require a model with endogenous crop choice, which is beyond the scope of the present article. We thus value cotton and inputs at their average level over the period considered. By contrast, intra-seasonal price variations matter, at least those occurring during the crop cycle. We address the issues related to intra-seasonal price variations in section 4.2 .

Table 1: Yield and rainfall data summary statistics

\begin{tabular}{lccccc}
\hline \multicolumn{1}{c}{ Whole period (1977-2010) } & Mean & Std. Dev. & Min. & Max. & N \\
\hline Annual cumulative rainfall (mm per year) & 950 & 227 & 412 & 1790 & 849 \\
Yield (kg/ha) & 1150 & 318 & 352 & 2352 & 849 \\
Cotton profit $^{\dagger}$ (CFA francs per ha) & 114847 & 50066 & -7400 & 294900 & 849 \\
\hline $\mathbf{1 9 9 1 - 2 0 0 4}$ sub-period & & & & & \\
\hline Annual cumulative rainfall (mm per year) & 953 & 211 & 491 & 1708 & 479 \\
Yield (kg/ha) & $1202^{* * *}$ & 297 & 414 & 2117 & 479 \\
Cotton profit * (CFA francs per ha) & $134323^{* * *}$ & 50542 & 4838 & 294900 & 479 \\
\hline \hline
\end{tabular}

$\dagger$ Profit for one hectare of cotton after input reimbursement, excluding labor.

Student test for the equality of the average 1991-2004 sub-period compared to the rest of the sample:

${ }^{*} p<.1,{ }^{* *} p<.05,{ }^{* * *} p<.01$ 


\subsection{Weather indices}

The role of weather in cotton growing in Western and Central Africa has been documented in previous studies. For instance, Blanc et al. (2008) pointed out the impact of the distribution and schedule of precipitation during the cotton growing season on long run yield plot observations in Mali. Blanc et al. (2008), Marteau et al. (2011) and Traore et al., 2014 show that the length of the rainy season, and more particularly its onset, are major determinants of cotton and cereal yield in the region. They have recently been found to be the major drivers of year-to-year and spatial variability of yields in the Cameroonian cotton zone (Sultan et al., 2010). It is explained mainly by the fact that the number of bolls (cotton fruit including the fibre and the seeds) and their size are proportional to the cotton tree growth and development, which itself is proportional to the length of the growing cycle.

We use the sowing dates reported by Sodecoton in the form of the share of the acreage sowed with cotton observed every 10 days, from May 20 to the end of July. We define the beginning of the season as the date for which half of the cotton area is already sown. The relationships between yields and observed sowing date is shown in Appendix F.

Table 2: Indices description.

\begin{tabular}{|c|c|c|}
\hline Index name & Description & Goodness of fit to yield $(\mathrm{r} 2)$ \\
\hline Length $_{o b s}$ after sowing & $\begin{array}{c}\text { Length of the growing cycle, from the observed } \\
\text { sowing date to the last rainfall }\end{array}$ & .11 \\
\hline Sowing date obs $_{\text {. }}$ & Observed sowing date, in days from the first of January & .16 \\
\hline
\end{tabular}

In table 2, we provide the definition of the two indices retained for their relatively high performance (cf. figure 7 in Appendix F for the relation between sowing date and cotton yield and profit), i.e. indices for which results will be displayed. We consider the length of the growing season and the sowing date in days for insuring against a short growing season or late sowing. In the latter case insurance covers against high values of the index (late sowing). This last index is very similar to the one used in the R4/HARITA projet in Ethiopia, which focuses on payouts if the season begins late and/or ends too early.

We have tested more complicated indices, described in Appendix B.1 and B.2. They are not presented in the results section since they did not perform better than the rather 
simple indices presented. The strength of simple indices over complex ones echoes the simplicity/complexity debate in the documentation about practical implementation. Complexity of the index indeed limits the transparency and acceptability of insurance and there is a trade-off with its capacity to reflect bad yield (basis risk). It is indeed preferable to choose indices belonging to farmers' mental representations so that they do not represent obstacles to implementation as would complex ones. For instance, the onset of the rainy season and the planting date are already widely used by farmers in the Sahel and will thus facilitate trust and understanding of the insurance product.

\subsection{Definition of rainfall zones}

Average annual cumulative rainfall varies between 600 and $1200 \mathrm{~mm}$ in the cotton producing area characterized by a Sudano-sahelian climate.

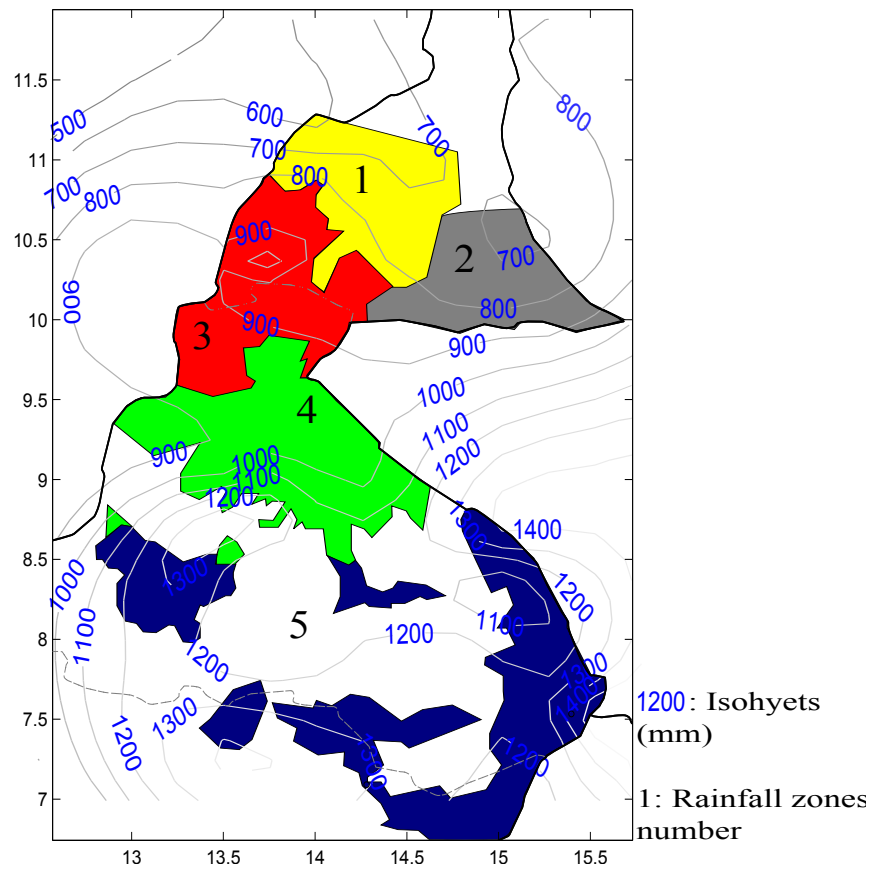

Figure 2: Rainfall zones based on annual cumulative rainfall: North: (1), North East (2), North West (3), Centre (4) and South (5) and isohyets (in mm for the 1970-2010 period). Source: authors calculations.

We define five rainfall zones in the following way: we sort Sectors by rainfall level, for the whole period (1991-2004), and regroup them into zones of similar size. The geograph- 


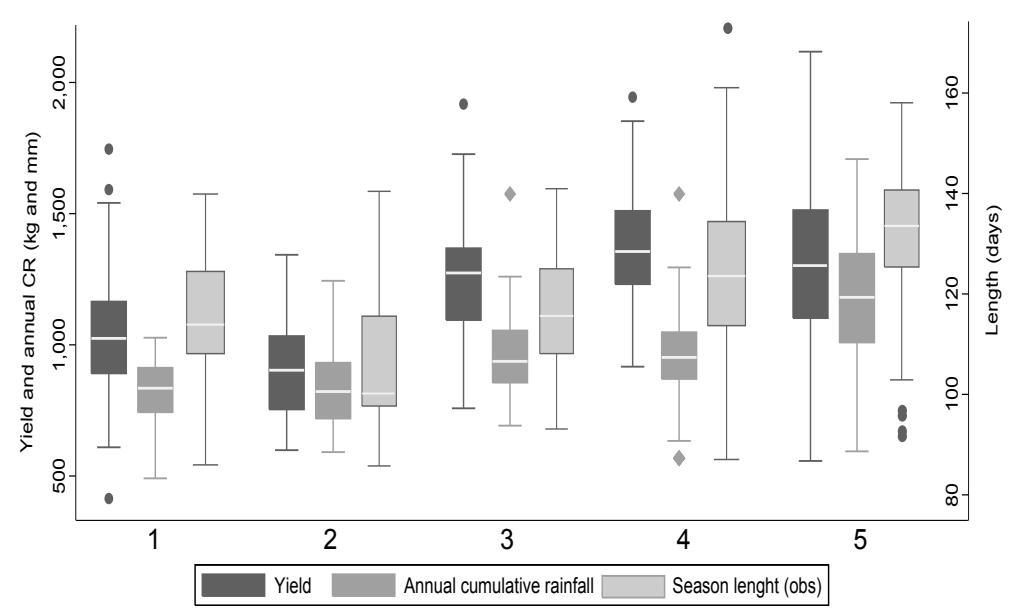

Figure 3: Boxplots of Yield, Annual rainfall and cotton growing season duration in different rainfall zones.

ical zoning of the cotton cultivation area is displayed in figure 2 and the distribution of yields, annual cumulative rainfall and length of the rainy season for each zone in figure 3 .

The rainfall zones have different average yields, cumulative rainfall and cotton growing seasonal lengths. The sowing and emerging dates are 10 to 15 days later in the two northern rainfall zones than in the three others. Since the length of the rainy season is acknowledged as being one of the major meteorological factors having an effect on yield, such a feature could explain part of the discrepancies among yields in different rainfall zones.

\subsection{Weather index-based insurance set up}

The indemnity is a step-wise linear function of the index with 3 parameters: the strike $(\mathrm{S})$, i.e. the threshold triggering indemnity payout; the maximum indemnity $(\mathrm{M})$ and $\lambda$, the slope-related parameter. We thus have the following indemnification function depending on $x_{i, t}$, the weather index realisation (as defined by Vedenov and Barnett, 2004):

$$
I_{i, t}\left(S, M, \lambda, x_{i, t}\right)= \begin{cases}M, & \text { if } x_{i, t} \leq \lambda . S \\ \frac{S-x_{i, t}}{S \times(1-\lambda)}, & \text { if } \lambda . S<x_{i, t}<S \\ 0, & \text { if } x_{i, t} \geq S\end{cases}
$$

When $\lambda$ equals one, the indemnity is either $M$ (when the index falls below the strike 
level) or 0 . The strike ideally should correspond to the level at which the meteorological factor becomes limiting.

We took this functional form because, to our knowledge, most index-based insurances presently implemented or studied ex ante are based on this precise contract shape. The insurer reimburses the difference between the usual income level and the estimated loss in income resulting from a yield loss, yield being proxied by the weather index realisation.

We use different objective functions to maximise farmers' expected utility and show that our results are robust to this choice. We consider both of the following objective functions, respectively a constant relative risk aversion (CRRA) utility function (equation 2) and a constant absolute risk aversion (CARA) utility function (equation 3). Results using the CARA objective function are displayed in Appendix D while those using the CRRA function are presented in the Results section. Utility functions are the following:

$$
\begin{gathered}
U_{C R R A}\left(\Pi_{i, t}\right)=\frac{\left(\Pi_{i, t}+w\right)^{(1-\rho)}}{(1-\rho)} \\
U_{C A R A}\left(\Pi_{i, t}\right)=\left(1-\exp \left(-\psi \times\left(\Pi_{i, t}+w\right)\right)\right)
\end{gathered}
$$

Both objective functions are standard in the economic literature. Following Gray et al. (2004), w corresponds to non-cotton production, the calibration of which is presented in Appendix A.2. $\rho$ and $\psi$ are the risk aversion parameters in each objective function, respectively constant relative risk aversion and constant absolute risk aversion parameters. Risk aversion is equivalent to inequality aversion in this context and we consider the agrometeorological relations to be ergodic since we assimilate spatial (Sectoral) variations to time variations.

Field work (Nov. and Dec. 2011) was carried out to calibrate the risk aversion parameter of the CRRA function (cf. Appendix A.1), from which the parameters of the CARA utility function can be inferred. Following Lien and Hardaker (2001), we assume that $\psi=\rho / W$, with $W=w+E[\Pi]$. We also calibrated $W$ using Sodecoton surveys from 2003, 2006, 2007, 2008 and 2009 (cf. Appendix A.2).

Given that $52 \%$ of our sample show a risk aversion greater than 1.16 and that gains were negligible for low risk aversion levels $(<1)$, we test a range of values between 1 (the 
approximate median value) and 3 for the CRRA function $(\rho=[1,2,3])$.

The certain equivalent income (CEI) with insurance corresponds to:

$$
\begin{array}{cc}
C E I_{C R R A}\left(\tilde{\Pi}^{I}\right)=\left((1-\rho) \times E U\left(\tilde{\Pi}^{I}\right)\right)^{\frac{1}{1-\rho}}-w, & \tilde{\Pi}^{I}=\left\{\Pi_{1}^{I}, \ldots, \Pi_{N}^{I}\right\} \\
C E I_{C A R A}\left(\tilde{\Pi}^{I}\right)=\left(\frac{1}{\psi}\right) \times \log \left(-E U\left(\tilde{\Pi}^{I}\right)-1\right)-w, & \tilde{\Pi}^{I}=\left\{\Pi_{1}^{I}, \ldots, \Pi_{N}^{I}\right\}
\end{array}
$$

with $E U(\tilde{\Pi})$ the expected utility of the vector of profit realisations $(\tilde{\Pi})$ and $N$ the number of observations over time and sectors. The insured profit $\left(\Pi^{I}\right)$ is the observed profit ( $\Pi$, as defined in section 3.1) minus the insurance premium plus the hypothetical indemnity:

$$
\Pi_{i, t}^{I}=\Pi_{i, t}-P\left(S^{*}, M^{*}, \lambda^{*}\right)+I_{i, t}\left(S^{*}, M^{*}, \lambda^{*}, x_{i, t}\right)
$$

with $x_{i, t}$ the realisation of the weather index in year $t$ and sector $i$. The premium includes the loading factor $\beta$, i.e. the insurer charge for risk loading and administrative costs, set at $10 \%$ of total indemnification, and a transaction cost (TC) for each indemnification, set exogenously to one percent of the average profit, corresponding to one day of rural wage.

$$
P=\frac{1}{N}\left[(1+\beta) \times \sum_{i} \sum_{t} I_{i, t}\left(S^{*}, M^{*}, \lambda^{*}, x_{i, t}\right)+T C \times \sum_{i} \sum_{t} F_{i, t}\right], \text { with } F_{i, t}=\left\{\begin{array}{l}
1 \text { if } I_{i, t}>0 \\
0 \text { if } I_{i, t}=0
\end{array}\right.
$$

We finally optimize the three insurance parameters in order to maximise expected utility and look at the gain in CEI depending on the index. The strike, i.e. the threshold of the meteorological index at which a payout is triggered, is bounded by a maximum indemnification occurrence rate of $25 \%$, corresponding to the insurer's maximum risk loading capacity. These parameter values are consistent with the cost of WII observed in the country with by far the most substantial experience: India (Chetaille et al., 2010). 


\subsection{Basis risk and certain equivalent income}

There is not much theoretical work on the definition of basis risk in the context of index insurance calibration. The Pearson correlation coefficient between weather and yield (or losses) time series is the only measure used for evaluating the basis risk empirically (see for instance Carter et al, 2007). Such a measure is imperfect because it does not depend on the payout function and the utility function which will determine the capacity of insurance to improve the allocation of resources.

The basis risk can be considered as the sum of three risks: first, the risk resulting from the index not being a perfect predictor of observed yield at a given geographical level (called design basis risk hereafter). Second, the spatial basis risk, recently put forward by Norton et al., 2012 on US data: the index may not capture the weather effectively experienced by the farmer, all the more so if the farmer is far from the weather station(s) that provide data on which index is calculated. Third, the idiosyncratic basis risk, stemming from heterogeneities among farmers (practices) or among plots (soil conditions). The intra-village yield variation is indeed often found to be high in developing countries, but also in high income countries (seminal paper of Townsend, 1994 and Claasen and Just, 2011). The distinctions between these three sources of basis risk depend on the insurance set-ups (crops insured, meteorological indices considered and their underlying data sources, etc.) and especially the geographical scale. The three estimate sources of basis risk are contingent upon the definition of the unit of insured area, that is to say, the size of the individual unit (a parcel being very different from a large farm) and the resolution of the data used (both for farming and meteorological conditions). Increasing the geographical unit where weather and yield conditions are observed will cause the difference between individual yield and area-yield to increase, due to both heterogeneous agrometeorological conditions and soil conditions. The issues arising when dealing with idiosyncratic basis risk in the case of a WII have been previously analysed in Leblois et al. (2013). We will here focus on only the design basis risk, as considering other types of basis risk will simply exacerbate the issues we are raising.

We propose a tractable definition of the design basis risk (DBR), based on the computation of a area-yield index that is the observation of the actual cotton yield at the same 
spatial level for which both yield data and weather indices are available. In our case this level is the Sodecoton 'sector', the lowest administrative unit for which data are available.

We thus consider the design basis risk as the difference in percentage of utility gain obtained by smoothing income through time and space and lowering the occurrence of bad cotton income through weather index insurance (WII) as compared to a area-yield index insurance with the same contract type. The latter is a hypothetical insurance contract based on yield observed at the Sector level. The contract has exactly the same shape as the payout function defined in section 3.4, and the same hypotheses ${ }^{6}$ as the WII contracts, except the index, which is the yield realisation. We will call it AYII (areayield index insurance) hereafter, considering this is the best contract possible under these hypotheses.

$$
B R=1-\frac{C E I\left(\tilde{\Pi}_{W I I}^{I}\right)}{C E I\left(\tilde{\Pi}_{A Y I I}^{I}\right)}
$$

\section{Results}

\subsection{Insurance gains and basis risk}

\subsubsection{Whole cotton area}

The first line of table 3 shows the gain in percent of CEI that an insurance based on a areayield index would bring to an agent with CRRA utiliy function, given our assumptions on the payout function presented in section 3.4. The rest of the table shows the gains of other indices as a share of this maximum gain, corresponding to (1-DBR). Results with a CARA utility function are very similar and are displayed in Appendix D.

The first line of table 5 shows that the benefit is always low, even for the AYII and high risk aversion. Moreover, we observe a very high basis risk exceeding $50 \%$ for most indices. The best performing indices are the length of the growing season and the sowing date itself. This last result is coherent with the existing agronomic literature presented in section 3.2 above. The better performance of the sowing date compared to the length of the growing period might be explained by the fact that late rains can bring down cotton

\footnotetext{
${ }^{6}$ The premium equals the sum of payouts plus $10 \%$ of loading factor and a transaction cost.
} 
Table 3: CEI gain (CRRA) of index insurances relative to area-yield index insurance (AYII) CEI gain from 1991 to 2004.

\begin{tabular}{lccc}
\hline \hline & $\rho=1$ & $\rho=2$ & $\rho=3$ \\
\hline \hline AYII CEI gain & $0.19 \%$ & $0.92 \%$ & $1.81 \%$ \\
\hline CEI gains relative to AYII & & & \\
Length $_{\text {obs }}$ after sowing & $\mathbf{2 6 . 2 5} \%$ & $\mathbf{3 3 . 6 6} \%$ & $\mathbf{3 7 . 2 5} \%$ \\
Sowing date $_{\text {obs }}$ & $\mathbf{3 4 . 9 8} \%$ & $\mathbf{5 0 . 6 9} \%$ & $\mathbf{5 2 . 4 6} \%$ \\
\hline \hline
\end{tabular}

We display in bold insurance contract simulations that reach at least $25 \%$ of the AYII gain, i.e. a basis risk below $75 \%$.

bolls and thus reduce yield. Hence, comparing two years with the same sowing date, the one with the longest season, i.e. with the latest rain, may either have higher or lower yield.

As mentioned above, we have tested other indices ${ }^{7}$, which all showed lower performance than those presented here. Indeed most of those indices were more complicated, hence more difficult to understand by potential clients, and none performed better.

As utility functions used may be complicated or imperfect we thought it could be useful to the reader to get simpler indicators of the risk reduction. As a comparison, the insurance contract (CRRA, with $\rho=2$ ) against a late sowing date reduces the coefficient of variation (standard deviation on mean) by only $3.9 \%$ while the AYII reduces it by $16.6 \%$ and it increases the first decile of income by only $1.95 \%$ while the AYII increases it by $19.6 \%$.

If, as in the present section, the same drought insurance contract is applied to a large area, some money is transferred from the wettest zones to the driest ones (crosssubsidisation). In order to show this we divided the cotton zone into 5 rainfall zones (RZ), which are more homogeneous in terms of weather (the underlying methodology is explained in section 3.3). As shown in table 4, the driest zones (in the North) are

\footnotetext{
${ }^{7}$ From the simplest to the most complicated: annual cumulative rainfall, the cumulative rainfall over the observed and simulated rainy season (onset and offset set according to Sivakumar, 1988 criterion) and the simulated growing phases (GDD accumulation and characteristics of cultivars), the same indices with daily rainfall bounded to $30 \mathrm{~mm}$, the length of the rainy season and the length of the cotton growing season, sum and maximum bi-monthly NDVI values over the rainy season and the NDVI values over October (the end of the season), the cumulative rainfall after cotton plant emergence and the observed duration of the growing season after emergence in days.
} 
highly subsidised, while the most humid (in the South) are highly taxed. Clearly, such an insurance contract would be refused by farmers in the South. Hence, splitting the cotton zone into different zones is required in order to insure against drought.

Table 4: Net subsidy rate (in percentage of the sum of premiums paid) of index-based insurances across the 5 rainfall zones (RZ), for $r h o=2$ (CRRA).

\begin{tabular}{|c|c|c|c|c|c|}
\hline & RZ 1 & RZ 2 & RZ 3 & RZ 4 & RZ 5 \\
\hline Length $_{\text {obs }}$ after sowing & $41.16 \%$ & $135.27 \%$ & $-86.02 \%$ & $-38.43 \%$ & $-40.94 \%$ \\
\hline Sowing date obs $_{\text {s }}$ & $108.98 \%$ & $139.31 \%$ & $-86.20 \%$ & $-59.49 \%$ & $-80.57 \%$ \\
\hline
\end{tabular}

\subsubsection{Rainfall zoning}

Up to this point, only one insurance contract (characterized by the three parameters: $S$, $\lambda$ and $M$ ) has been considered for the whole Cameroonian cotton zone. We will now calibrate distinct insurance contracts for our five more homogeneous rainfall zones. Table 5 displays, for each index, the in-sample and out-of-sample (in italic) CEI gains with a CRRA utility function when optimizing insurance in each of the rainfall zones ${ }^{8}$. In-sample contract calibrations are displayed in table 10, table 11 and table 12 in Appendix C.

The in-sample gain is the gain of an insurance contract calibrated and tested on the same data. This estimation may thus suffer from over-fitting, which could lead to overestimating the insurance gain. Cross validation makes it possible to consider the gains of an insurance contract that would be tested on a different sample from the one on which it is calibrated. Different cross validation techniques could be used such as the leave-one-out procedure (as in Berg et al., 2009 and Leblois et al., 2013) or the use of a different period (Vedenov and Barnett, 2004) or sample (Chantarat et al., 2013) to calibrate the index and to assess its performance. In this article, we use a leave-one-out technique, leaving one sector of each rainfall zone for calibration and testing the data. Selecting spatial cross validation seems more appropriate than time, given the underlying trends potentially existing in the series.

\footnotetext{
8 An alternative would have been to standardise indices by sector i.e. to consider the ratio of the deviation of each observation to the Sector average yield on its standard deviation. Still, it did not significantly improve the results, presumably because the weather index distribution differs across rainfall zones.
} 
Table 5: In-sample and out-of-sample* estimated CEI gain (CRRA) of index insurances relative to AYII absolute gain, among different rainfall zones, from 1991 to 2004.

\begin{tabular}{|c|c|c|c|}
\hline & $\rho=1$ & $\rho=2$ & $\rho=3$ \\
\hline \multicolumn{4}{|c|}{ First rainfall zone } \\
\hline \multirow[t]{2}{*}{ AYII CEI gain } & $.28 \%$ & $1.31 \%$ & $2.57 \%$ \\
\hline & $.25 \%$ & $1.30 \%$ & $2.40 \%$ \\
\hline \multirow[t]{2}{*}{ Length $_{o b s}$ after sowing } & $6.52 \%$ & $24.47 \%$ & $34.76 \%$ \\
\hline & $-40.67 \%$ & $37.10 \%$ & $24.72 \%$ \\
\hline \multirow{2}{*}{ Sowing date ${ }_{o b s}$} & $0 \%$ & $37.58 \%$ & $45.64 \%$ \\
\hline & $49.82 \%$ & $97.74 \%$ & $91.68 \%$ \\
\hline \multicolumn{4}{|c|}{ Second rainfall zone } \\
\hline \multirow[t]{2}{*}{ AYII CEI gain } & $.05 \%$ & $.67 \%$ & $1.54 \%$ \\
\hline & $.05 \%$ & $.63 \%$ & $1.43 \%$ \\
\hline \multirow[t]{2}{*}{ Length $_{o b s}$ after sowing } & $0 \%$ & $20.22 \%$ & $24.85 \%$ \\
\hline & $0 \%$ & $39.96 \%$ & $49.90 \%$ \\
\hline \multirow[t]{2}{*}{ Sowing date ${ }_{o b s}$} & $0 \%$ & $44.86 \%$ & $54.61 \%$ \\
\hline & $0 \%$ & $48.72 \%$ & $69.06 \%$ \\
\hline \multicolumn{4}{|c|}{ Third rainfall zone } \\
\hline \multirow[t]{2}{*}{ AYII CEI gain } & $.15 \%$ & $.99 \%$ & $2.00 \%$ \\
\hline & $.18 \%$ & $.99 \%$ & $2.06 \%$ \\
\hline \multirow[t]{2}{*}{ Length $_{o b s}$ after sowing } & $0 \%$ & $0 \%$ & $.89 \%$ \\
\hline & $0 \%$ & $-178.99 \%$ & $-147.85 \%$ \\
\hline \multirow[t]{2}{*}{ Sowing date ${ }_{o b s}$} & $0 \%$ & $0 \%$ & $0 \%$ \\
\hline & $-410.55 \%$ & $-216.22 \%$ & $-158.67 \%$ \\
\hline \multicolumn{4}{|c|}{ Fourth rainfall zone } \\
\hline \multirow[t]{2}{*}{ AYII CEI gain } & $.51 \%$ & $.95 \%$ & $1.96 \%$ \\
\hline & $.09 \%$ & $.71 \%$ & $1.54 \%$ \\
\hline \multirow[t]{2}{*}{ Length $_{\text {obs }}$ after sowing } & $0 \%$ & $0 \%$ & $0 \%$ \\
\hline & $0 \%$ & $0 \%$ & $0 \%$ \\
\hline \multirow[t]{2}{*}{ Sowing date ${ }_{o b s}$} & $0 \%$ & $0 \%$ & $0 \%$ \\
\hline & $0 \%$ & $0 \%$ & $0 \%$ \\
\hline \multicolumn{4}{|c|}{ Fifth rainfall zone } \\
\hline \multirow[t]{2}{*}{ AYII CEI gain } & $.20 \%$ & $1.49 \%$ & $2.35 \%$ \\
\hline & $.10 \%$ & $.75 \%$ & $1.59 \%$ \\
\hline \multirow[t]{2}{*}{ Length $_{\text {obs }}$ after sowing } & $\mathbf{5 7 . 4 5 \%}$ & $46.60 \%$ & $44.71 \%$ \\
\hline & $183.27 \%$ & $-25.54 \%$ & $48.40 \%$ \\
\hline \multirow[t]{2}{*}{ Sowing date ${ }_{o b s}$} & $69.48 \%$ & $49.91 \%$ & $46.82 \%$ \\
\hline & $-147.51 \%$ & $-10.80 \%$ & $78.99 \%$ \\
\hline
\end{tabular}

${ }^{*}$ Leave-one-out estimations are displayed in italic.

We display in bold insurance contract simulations that reach at least $25 \%$, i.e. a basis risk below $75 \%$. 
For each sector, out-of-sample estimates are calibrated on the 6 to 8 other sectors of the same rainfall zone. The optimisation constraints concerning the insurer loading factor no longer holds on the test sample (but only on the calibration sample). Thus, insurer profits (losses) that are above (below) the $10 \%$ charging rate are equally redistributed to (taken from) each sector. This artificially keeps the insurer out-of-sample gain equal to the in-sample case and thus allows comparison with in-sample calibration estimates. In out-of sample, the insurance parameters can differ among sectors, which explains the sometimes higher results in out-of-sample than in in-sample.

The interest of out-of-sample estimations appears in particular for the fifth rainfall zone: while an insurance based on the length of the rainy season seems advantageous to farmers in the in-sample estimation, such is not the case with the out-of-sample estimation for a risk aversion parameter below 3. Since this zone is the most humid, the good result of the in-sample estimation is probably due to over-fitting.

Looking at optimisations among different rainfall zones leads to a different picture than optimisation over the whole cotton area. First, in the third and the fourth rainfall zones, no index can be used to hedge farmers. In the other zones, the length of the growing season and the observed sowing date remain the best performing indices. They are the only indices that lead to significant positive out-of-sample CEI gain estimations.

In other contexts, using the actual sowing date in an insurance contract is difficult because it cannot be observed costlessly by the insurer. However, in the case of cotton in French speaking West Africa, production relies mainly on interlinking input-credit schemes taking place before sowing and obliging the cotton company to follow production in each production group. As mentioned by De Bock et al. (2010), cotton national monopsonies (i.e. Mali in their case and Cameroon in ours) already gather information about the sowing date in each region. The sowing date would thus be available at no cost to the department of production at Sodecoton. Under those circumstances observing the sowing date, making it transparent and free of any distortion and including it in an insurance contract would not be so costly.

Insuring against a declared sowing date could create agency issues: moral hazard in particular. However, in our case, the sowing date is aggregated at the Sector level (about 50 GP, each representing about 4000 producers). This means that a producer, and even 
a coordination of producers within a GP, cannot influence (and thus distort) the average sowing date at the Sector level by declaring a later date or by sowing later than optimally. Moreover, the sowing date is not only declared by farmers but also observed by Sodecoton agents.

\subsection{Implicit insurance against intra-seasonal price variations}

As mentioned earlier (in section 2.2), as Sodecoton announces the harvest purchasing price before sowing, the firm insures farmers against intra-seasonal variations of the international price. Furthermore, looking at the variation of Sectoral yields and intra-seasonal international cotton price variations during the 1991-2004 period, the latter vary twice as much as the former (coefficient of variation of 0.28 for yield vs. 0.42 for intra-seasonal international cotton price). This suggests that cotton growing profit risk is driven mainly by intra-seasonal price variations and that production risk only represents the second source of risk.

Admittedly, this observation is obtained by considering the 1993-1994 season during which the CFA franc value was halved. However, a sample without this very specific year still shows a slightly higher coefficient of variation than yield (0.32 vs. 0.28). This also holds when considering the 1977-2010 period, and when dropping the specific years 1993-1994 and 2010 (during which the highest cotton price was observed).

Sodecoton possibly offers such implicit price insurance at a cost, albeit a cost which is very difficult to compute. We compare the gain of a free insurance mechanism (we thus call it stabilisation) compensating for yield and for intra-seasonal price variations. This does not affect the argument that the level of the price risk is significant, especially relative to other risks.

We compute the relative variation between the average prices during the 4-month period after harvest and compared it to the 4 month period before sowing. We use this relative variation to simulate the profit variations farmers would face due to intra-seasonal price variations if the cotton company did not insure them against intra-seasonal price variations. We attribute this variation to the observed producer price and compute the gain in terms of CEI of the implicit insurance offered by the cotton company. 
We compare the gains of two ways of reducing risk: going from a situation where farmers face the same price variation as the international price to a situation where they already know the price at sowing; going from a situation where yields are varying to a situation where the yield is equal to the average Sectoral yield for the whole period. We thus assess and compare the CEI gains of removing every yield variation and every intra-seasonal price variation.

Table 6: CEI gain of intra-seasonal price and yield stabilisation (in-sample parameter calibration) in each rainfall zone (RZ) and in the whole cotton zone (CZ)

\begin{tabular}{lcccccc|c}
\hline \hline & & RZ1 & RZ2 & RZ3 & RZ4 & RZ5 & CZ \\
\hline$(1)$ & CEI gain of intra-seasonal price stab. (CRRA, $\rho=2)$ & $10.28 \%$ & $11.33 \%$ & $11.84 \%$ & $12.85 \%$ & $17.85 \%$ & $12.98 \%$ \\
$(2)$ & CEI gain of intra-seasonal price stab. (CARA, $\psi=2 / \mathrm{W})$ & $5.41 \%$ & $4.96 \%$ & $6.66 \%$ & $7.23 \%$ & $8.84 \%$ & $6.72 \%$ \\
\hline$(3)$ & CEI gain of yield stab. (CRRA, $\rho=2)$ & $3.09 \%$ & $.74 \%$ & $2.88 \%$ & $1.91 \%$ & $3.75 \%$ & $2.46 \%$ \\
$(4)$ & CEI gain of yield stab. (CARA, $\psi=2 / \mathrm{W})$ & $1.49 \%$ & $.40 \%$ & $1.07 \%$ & $1.00 \%$ & $1.77 \%$ & $1.16 \%$ \\
\hline$(3) /(1)$ & & 3.33 & 15.31 & 4.11 & 6.73 & 4.76 & 5.28 \\
$(4) /(2)$ & & 3.63 & 12.40 & 6.22 & 7.23 & 4.99 & 5.79 \\
\hline \hline
\end{tabular}

Table 6 shows the gain due to the stabilisation of intra-seasonal cotton price variations and the gain of a stabilisation of Sectoral yield levels with the observed yield distribution in each rainfall zone. The last column of table 6 shows the CEI gain afforded by the stabilisation of the intra-seasonal cotton international price and yields for the whole cotton zone for the same period. The stabilisation of yield brings a much lower gain than the stabilisation of intra-seasonal variation of the international cotton price already hedged by Sodecoton: depending on the rainfall zone and utility function, the gain from the former is between 3 and 15 times that of the latter.

These results hold when considering simpler indicators of risk reduction: while stabilizing prices reduces (increases) the coefficient of variation (first decile) of the income distribution of $59 \%(9.4 \%)$, stabilizing yield is only reduces (increases) it of $20 \%(3.6 \%)$.

\section{Conclusion}

Micro-insurance, and in particular weather-index insurance, is currently strongly supported by development agencies and international institutions. In this paper, we provide an ex ante assessment of weather-index insurance for risk-averse cotton farmers in 
Cameroon. We compute the benefit of such insurance for several weather indices, three levels of risk aversion (the distribution of which was assessed through field work) and two different utility functions. To avoid over-fitting, we use an out-of-sample estimation technique.

Our results calls for caution about the benefits of weather-index insurance, at least in the context we study. Firstly, even if the weather index were a perfect predictor of cotton yield (which is impossible), the benefit for farmers in terms of certain equivalent income would be less than $3 \%$. This is much less than the benefit of the hedging against intra-annual price fluctuations currently provided by the national cotton company. This result highlight the necessity of offering price stabilization schemes for cash crop farmers in other countries. Such schemes could for instance be implemented using option or futures hedging against intra-seasonal variations of the international price within contract farming schemes.

The insurance could however play a role on the risk taking of farmers, and increase average yields in the long run by giving incentive to use more risky but more productive technologies. In addition, insurance could address the risk aversion of lenders, and hence open access to credit for inputs and foster intensification. Such effects are not taken into account here and could be significant. Dercon and Christiaensen (2011) indeed report a strong link between willingness to take up fertilizer and weather risk in Ethiopia and the opportunity cost of not using risky technology have been evaluated at about $30 \%$ of profits in India by Rosenzweig and Binswanger (1993). Yet, insurance can ease input use and intensification only if it significantly reduces weather risk for farmers; otherwise, farmers will remain reluctant to use risk-increasing inputs and lenders will have no reason to ease access to credit. Unfortunately, our conclusions on this point are not really positive.

Indeed, we show that all weather indices are highly imperfect. In two out of the five rainfall zones defined for this study, no weather index could provide a benefit to farmers. In the remaining three rainfall zones, even the best indices present a design basis risk of about one half, i.e. an insurance based on such indices would provide only half of the (already low) benefit of an area-yield index insurance, that provides a perfect hedging against yield variations. Moreover when looking at the risk reduction using simpler indicators, such as the standard deviation and the first decile of income distribution, this conclusion remains. 
Therefore although the insurance contract reduces risk, this reduction seems too small to allow a significant reduction in the default rate of farmers, hence a significant increase in access to credit. In the case of cotton in Cameroon, access to input credit is however already widespread.

On a more positive note, we conclude that the best indices are very simple, hence easily understood by farmers. Furthermore, these indices (the length of the rainy season and the sowing date) are consistent with the agronomic literature, which concludes that they are better predictors of cotton yields than e.g. cumulated rainfall. A reduction of weather risk is still welcome since indebted farmers cannot use Sodecoton inputs, even for staple crops, and because there are very few available alternative input providers. Moreover, national cotton companies could distribute such insurance products at a relatively low cost since they already sell inputs credits to, and buy cotton from, all cotton producers. All in all, while providing hedging products to small-scale farmers in low-income countries is certainly welcome, due care should be given to the quantification of the different risks these farmers face and to the institutions which could provide, or already provide, these hedging products.

\section{References}

Barnett, B. J., Barrett, C. B., Skees, J. R., October 2008. Poverty traps and index-based risk transfer products. World Development 36 (10), 1766-1785.

URL http://ideas.repec.org/a/eee/wdevel/v36y2008i10p1766-1785.html

Baron, C., Sultan, B., Maud, B., Sarr, B., Traoré, S., Lebel, T., Janicot, S., Dingkuhn, M., 2005. From gcm grid cell to agricultural plot: scale issues affecting modelling of climate impact. Phil. Trans. R. Soc. 360, 2095-2108.

Bella-Medjo (Tsogo), M., 2009. Analyse multi-échelle de la variabilité pluviométrique au cameroun et ses conséquences sur le rendement du coton. Ph.D. thesis, Université Pierre et Marie Curie.

Berg, A., Quirion, P., Sultan, B., 2009. Can weather index drought insurance benefit to 
least developed countries' farmers? a case study on burkina faso. Weather, Climate and Society 1, 71-84.

Binswanger, H. P., December 1981. Attitudes toward risk: Theoretical implications of an experiment in rural india. Economic Journal 91 (364), 867-90.

URL http://ideas.repec.org/a/ecj/econjl/v91y1981i364p867-90.html

Binswanger-Mkhize, H. P., 2012. Is there too much hype about index-based agricultural insurance? Journal of Development Studies 48 (2), 187-200.

URL http://www.tandfonline.com/doi/abs/10.1080/00220388.2011.625411

Blanc, E., Quirion, P., Strobl, E., 2008. The climatic determinants of cotton yields: Evidence from a plot in west africa. Agricultural and Forest Meteorology 148 (6-7), 1093 $-1100$.

Breustedt, G., Bokusheva, R., Heidelbach, O., 2008. Evaluating the potential of index insurance schemes to reduce crop yield risk in an arid region. Journal of Agricultural Economics 59 (2), 312-328.

URL http://dx.doi.org/10.1111/j.1477-9552.2007.00152.x

Bryan, G., 2012. Social networks and the decision to insure: Evidence from randomized experiments in china. Tech. rep., University of California Berkeley, mimeo.

Cai, J., Janvry, A. D., Sadoulet, E., 2012. Social networks and the decision to insure. Tech. rep., Berkeley University, mimeo.

Carter, M. R., Galarza, F., Boucher, S., Nov. 2007. Underwriting area-based yield insurance to crowd-in credit supply and demand. MPRA Paper 24326, University Library of Munich, Germany.

URL http://ideas.repec.org/p/pra/mprapa/24326.html

Chantarat, S., Mude, A. G., Barrett, C. B., Carter, M. R., 03 2013. Designing indexbased livestock insurance for managing asset risk in northern kenya. Journal of Risk \& Insurance 80 (1), 205-237.

URL http://ideas.repec.org/a/bla/jrinsu/v80y2013i1p205-237.html 
Chetaille, A., Duffau, A., Lagandré, D., Horréard, G., Oggeri, B., Rozenkopf, I., 2010. Gestion de risques agricoles par les petits producteurs, focus sur l'assurance-récolte indicielle et le warrantage. Tech. rep., GRET.

Claassen, R., Just, R. E., 2011. Heterogeneity and distributional form of farm-level yields. American Journal of Agricultural Economics 93 (1), 144-160.

URL http://ajae.oxfordjournals.org/content/93/1/144.abstract

Cole, S., Giné, X., Tobacman, J., Topalova, P., Townsend, R., Vickery, J., 2013. Barriers to household risk management: Evidence from india. American Economic Journal: Applied Economics 5 (1), 104-35.

URL http://www . aeaweb.org/articles.php?doi=10.1257/app.5.1.104

Crétenet, M., Dessauw, D., 2006. Production de coton-graine de qualité, guide technique no.1. Tech. rep., CIRAD.

De Bock, O., Carter, M., Guirkinger, C., Laajaj, R., 2010. étude de faisabilité: Quels mécanismes de micro-assurance privilégier pour les producteurs de coton au mali ? Tech. rep., Centre de Recherche en Economie du Développement, FUNDP Département de sciences économiques.

Delpeuch, C., Leblois, A., 2013. Sub-saharan african cotton policies in retrospect. Development Policy Review 31, 617-642.

Dercon, S., Christiaensen, L., November 2011. Consumption risk, technology adoption and poverty traps: Evidence from ethiopia. Journal of Development Economics 96 (2), $159-173$.

URL http://ideas.repec.org/a/eee/deveco/v96y2011i2p159-173.html

Dessauw, D., Hau, B., 2008. Cotton breeding in french-speaking africa: Milestones and prospectss. In: Invited paper for the Plant Breeding and Genetics research topic.

Elabed, G., Bellemare, M. F., Carter, M. R., Guirkinger, C., 2013. Managing basis risk with multiscale index insurance. Agricultural Economics 44 (4-5), 419-431.

URL http://dx.doi.org/10.1111/agec.12025 
Folefack, D. P., Kaminski, J., Enam, J., 2011. Note sur le contexte historique et gestion de la filière cotonnière au cameroun. Tech. rep., mimeo.

Freeland, J. T. B., Pettigrew, B., Thaxton, P., Andrews, G. L., 2006. Chapter 13a in guide to agricultural meteorological practices. In: Agrometeorology and cotton production.

Giné, X., Karlan, D., Ngatia, M., 2012. Social networks, financial literacy and index insurance. Tech. rep., Yale.

Giné, X., Townsend, R., Vickery, J., October 2008. Patterns of rainfall insurance participation in rural india. World Bank Economic Review 22 (3), 539-566.

URL http://ideas.repec.org/a/oup/wbecrv/v22y2008i3p539-566.html

Giné, X., Yang, D., 2009. Insurance, credit, and technology adoption: Field experimental evidence from malawi. Journal of Development Economics 89, 1-11.

Gray, A. W., Boehlje, M. D., Gloy, B. A., Slinsky, S. P., 2004. How u.s. farm programs and crop revenue insurance affect returns to farm land. Applied Economic Perspectives and Policy 26 (2), 238-253.

URL http://aepp.oxfordjournals.org/content/26/2/238. abstract

Hayes, M., Decker, W., 1996. Using noaa avhrr data to estimate maize production in the united states corn belt. International Journal of Remote Sensing 17, 3189-3200.

Hill, R. V., Hoddinott, J., Kumar, N., 2011. Adoption of weather index insurance: Learning from willingness to pay among a panel of households in rural ethiopia. IFPRI discussion papers 1088, International Food Policy Research Institute (IFPRI). URL http://ideas.repec.org/p/fpr/ifprid/1088.html

Holt, C. A., Laury, S. K., 2002. Risk aversion and incentive effects. American Economic Review 92, 1644-1655.

International Cotton Advisory Committee (ICAC), December 2007. Global warming and cotton production part 1 . Tech. rep.

International Cotton Advisory Committee (ICAC), March 2009. Global warming and cotton production part 2 . Tech. rep. 
Kaminski, J., Enam, J., Folefack, D. P., 2011. Hétérogénéité de la performance contractuelle dans une filière intégre : cas de la filière cotonnière camerounaise. Tech. rep., mimeo.

Karlan, D., Morduch, J., 2010. Access to Finance. Vol. 5 of Handbook of Development Economics. Elsevier, Ch. 0, pp. 4703-4784.

URL http://ideas.repec.org/h/eee/devchp/v5y2010icp4703-4784.html

Karlan, D., Osei, R., Osei-Akoto, I., Udry, C., 2012. Agricultural decisions after relaxing credit and risk constraints. Tech. rep., Yale University, mimeo.

Leblois, A., Quirion, P., Alhassane, A., Traoré, S., 2013. Weather index drought insurance: An ex ante evaluation for millet growers in niger. Environmental and Resource Economics, 1-25.

URL http://dx.doi.org/10.1007/s10640-013-9641-3

Levrat, R., 2010. Culture commerciale et développement rural l'exemple du coton au Nord-Cameroun depuis 1950. L'Harmattan.

Lien, G., Hardaker, J., 2001. Whole-farm planning under uncertainty: impacts of subsidy scheme and utility function on portfolio choice in norwegian agriculture. European Review of Agricultural Economics 28 (1), 17-36.

URL http://erae.oxfordjournals .org/content/28/1/17. abstract

Makdissi, P., Wodon, Q., 2004. Price liberalization and farmer welfare under risk aversion: Cotton in benin and ivory coast. Cahiers de recherche 04-09, Département d'Economie de la Faculte d'administration l'Universite de Sherbrooke.

URL http://ideas.repec.org/p/shr/wpaper/04-09.html

Marteau, R., Sultan, B., Moron, V., Alhassane, A., Baron, C., Traoré, S. B., 2011. The onset of the rainy season and farmers sowing strategy for pearl millet cultivation in southwest niger. Agricultural and Forest Meteorology 151 (10), 1356 - 1369.

URL http://www.sciencedirect.com/science/article/pii/S0168192311001766 
Maselli, F., Conese, C., Petkov, L., Gialabert, M., 1993. Environmental monitoring and crop forecasting in the sahel trought the use of noaa ndvi data. a case study: Niger 1986-89. International Journal of Remote Sensing 14, 3471-3487.

McLaurin, M. K., Turvey, C. G., 2012. Applicability of the Normalized Difference Vegetation Index (NDVI) in Index-Based Crop Insurance Design. Weather Climate and Society, 271-284.

Meroni, M., Brown, M., 2012. Remote sensing for vegetation monitroing: potential applications for index insurance. JRC, Ispra, ftp://mars.jrc.ec.europa.eu/index-insurancemeeting/presentations/7_meroni_brown.pdf.

Mobarak, A. M., Rosenzweig, M. R., 2013. Informal risk sharing, index insurance, and risk taking in developing countries. American Economic Review 103 (3), 375-80.

URL http://www . aeaweb.org/articles.php?doi=10.1257/aer.103.3.375

Norton, M. T., Turvey, C. G., Osgood, D. E., 2012. Quantifying spatial basis risk for weather index insurance. The Journal of Risk Finance 14, 20-34.

Pinzon, J., Brown, M., Tucker, C., 2005. Satellite time series correction of orbital drift artifacts using empirical mode decomposition. In: N. Huang (Editor), Hilbert-Huang Transform: Introduction and Applications.

Rosenzweig, M. R., Binswanger, H. P., January 1993. Wealth, weather risk and the composition and profitability of agricultural investments. Economic Journal 103 (416), 56-78. URL http://ideas.repec.org/a/ecj/econjl/v103y1993i416p56-78.html

Roudier, P., Sultan, B., Quirion, P., Berg, A., 2011. The impact of future climate change on west african crop yields: What does the recent literature say? Global Environmental Change 21 (3), $1073-1083$.

URL http://www.sciencedirect.com/science/article/pii/S0959378011000677

Shepard, D., 1968. A two-dimensional interpolation function for irregularly-spaced data. In: Proceedings of the 1968 23rd ACM national conference. ACM '68. ACM, New York, NY, USA, pp. 517-524.

URL http://doi.acm.org/10.1145/800186.810616 
Sivakumar, M. V. K., 1988. Predicting rainy season potential from the onset of rains in southern sahelian and sudanian climatic zones of west africa. Agricultural and Forest Meteorology 42 (4), $295-305$.

URL http://www.sciencedirect.com/science/article/B6V8W-488G6NR-W/2/8e4ea6b119bb561

Sultan, B., Bella-Medjo, M., Berg, A., Quirion, P., Janicot, S., 2010. Multi-scales and multi-sites analyses of the role of rainfall in cotton yields in west africa. International Journal of Climatology 30, 58-71.

Townsend, R. M., 1994. Risk and insurance in village india. Econometrica 62 (3), pp. $539-591$.

URL http://www.jstor.org/stable/2951659

Traore, B., van Wijk, M. T., Descheemaeker, K., Corbeels, M., Rufino, M. C., Giller, K. E., 2014. Evaluation of climate adaptation options for sudano-sahelian cropping systems. Field Crops Research 156 (0), 63 - 75.

URL http://www.sciencedirect.com/science/article/pii/S0378429013003651

Vedenov, D. V., Barnett, B. J., 2004. Efficiency of weather derivates as primary crop insurance instruments. Journal of Agricultural and Resource Economics 29 (3), 387403.

Yesuf, M., Bluffstone, R. A., 2009. Poverty, risk aversion, and path dependence in lowincome countries: Experimental evidence from ethiopia. American Journal of Agricultural Economics 91 (4), 1022-1037.

URL http://ideas.repec.org/a/oup/ajagec/v91y2009i4p1022-1037.html

\section{A Model calibration}

\section{A.1 Risk aversion}

A survey was implemented in groups of producers situated in 6 different locations ${ }^{9}$, each in one region, out of the nine administrative regions of the Sodecoton (cf. section 3.1).

\footnotetext{
9 The location of those six villages is displayed in figure 5.
} 
15 cotton farmers were randomly selected in each groups, i.e. randomly taken out of an exhaustive list of cotton farmers, which is detained by the Sodecoton operator in each village in order to manage input distribution each year. The core of the survey was designed to evaluate income and technical agronomic practices. Those producers were asked to come back at the end of the survey and lottery games were played in groups of 10 to 15 people. We used a typical Holt and Laury (2002) lottery ${ }^{10}$ apart from the fact that we did not ask for a switching point but played sequentially each of the 5 lottery games. In each game farmers were asked to choose among two lotteries (one risky and one safe) for a given probability of the bad outcome. It thus allowed the respondent to show time inconsistent choices, ensuring that she/he understood the framework and revealed stable preferences.

The 5 paired lottery choices are displayed in table 7 . At each step the farmers had to choose between a safe (I) and a risky (II) bet, both constituted of two options: a good and a bad harvest. Each option was illustrated by a schematic representation of realistic cotton production in good and bad years. The gains indeed represent the approximate average yield (in $\mathrm{kg}$ ) for $1 / 4$ of an hectare, the unit historically used by all farmers and Sodecoton for input credit, plot management etc. The gains were displayed in a very simple and schematic way in order to fit potentially low ability of some farmers to read and to understand a chart, given the low average educational attainment in the population. For each lottery game, the choices are associated with different average gains, probabilities were represented by a bucket and ten balls (red for a bad harvest and black for a good harvest). When all participants had made their choice, the realisation of the outcome (good vs. bad harvest) was randomly drawn by children of the village or a voluntary lottery player picking one ball out of the bucket.

The games were played and actual gains were offered at the end. Players were informed, at the beginning of the game that they would earn between 500 and 1500 CFA francs, 1000 CFA francs representing one day of legal minimum wage in Cameroon. We began with the lottery choice associated with equal probabilities, for which the safer option is

\footnotetext{
10 The difference of Table 4 with the Binswanger (1981) lottery, which is the most common lottery
} type in the literature, is that option gains are fixed and probabilities changing (opposite in a Binswanger lottery where probability of occurence of each option is fixed but gains changing on each line). 
Table 7: Lotteries options

\begin{tabular}{|l||c|c||c|c||c|c|}
\hline \multicolumn{1}{|l}{ I } \\
\begin{tabular}{|l|c|c|c|c|c|} 
Number of BB (prob. \\
of a good outcome)
\end{tabular} & RB & BB & RB & BB & $\begin{array}{c}\text { Difference (II-I) of } \\
\text { expected gains }\end{array}$ & $\begin{array}{c}\text { Risk aversion (CRRA) } \\
\text { when switching } \\
\text { from I to II }\end{array}$ \\
\hline $5 / 10$ & 150 & 250 & 50 & 350 & 0 & $\leq 0$ \\
\hline $6 / 10$ & 150 & 250 & 50 & 350 & 20 & ] $0,0.3512]$ \\
\hline $7 / 10$ & 150 & 250 & 50 & 350 & 40 & ] $0.3512,0.7236]$ \\
\hline $8 / 10$ & 150 & 250 & 50 & 350 & 60 & ] $0.7236,1.1643]$ \\
\hline $9 / 10$ & 150 & 250 & 50 & 350 & 80 & ] $1.1643,1.7681]$ \\
\hline & & & & & & $>1.7681$ \\
\hline
\end{tabular}

BB goes for black balls and RB for red balls

more interesting. Then, in each game, the relative interest of the risky option increased by raising the probability of a good harvest. We thus can compute the risk aversion level using the switching point from the safe to the risky option (or the absence of switching point).

We drop each respondent that showed an inconsistent choice ${ }^{11}$ among the set of independent lottery choices representing $20 \%$ of the sample: 16 individuals on 80 . We choose the average of each interval extremity as an approximation for $\rho$, as it is done in the literature (e.g. Yesuf and Bluntstone, 2009).

Following the methodology presented above, we find that $20 \%$ of the sample $(\mathrm{N}=64)$ shows a risk aversion below or equal to .72, and $38 \%$ a risk aversion greater than 1.77 under CRRA hypothesis. We display the distribution of the individual relative risk aversion of farmers of the 6 villages in figure 4 .

\section{A.2 Other incomes}

We use three surveys ran by Sodecoton in order to follow and evaluate farmers' agronomical practices and covering the 2003-2004, 2006-2007 and 2009-2010 growing seasons. We also use recall data for the 2007 and 2008 growing season from the last survey. The locations of surveyed clusters (GPs) are distributed across the whole zone, as displayed in figure 5. We compute the share of cotton-related income in on-farm income for 5 growing

\footnotetext{
${ }^{11}$ For instance a respondent that shows switching points indicating a risk aversion parameter greater than 1.7236 and below or equal to .3512 to is dropped.
} 


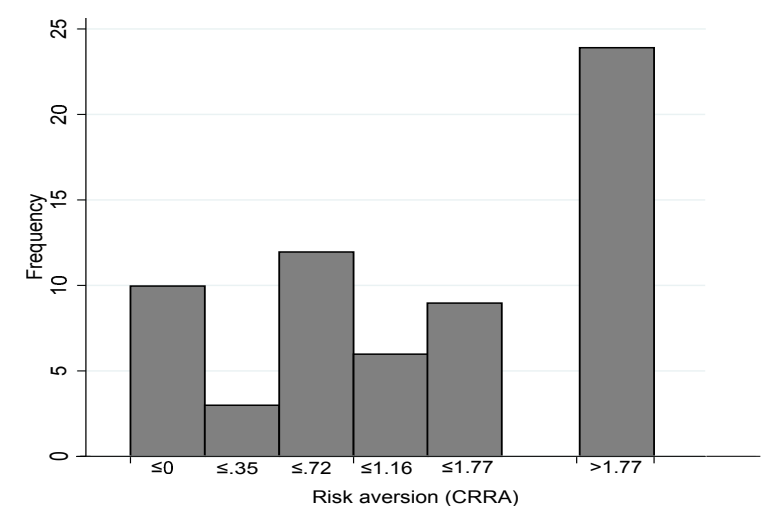

Figure 4: Distribution of relative risk aversion (CRRA) parameter density $(\mathrm{N}=64)$.

seasons. Cotton is priced at the average annual purchasing price of the Sodecoton and the production of major crops (cotton, traditional and elaborated cultivars of sorghum, groundnut, maize, cowpea) at the price observed in each Sodecoton region for a given year.

Table 8: On-farm and cotton income of cotton producers during the 2003-2010 period (in thousands of CFA francs)

\begin{tabular}{lccccc}
\hline \multicolumn{1}{c}{ Variable } & Mean & Std. Dev. & Min. & Max. & N \\
\hline Cotton income & 246.064 & 278.751 & 185 & 4525.1 & 5190 \\
Total income & 606.546 & 661.70 & 587 & 9520.68 & 5190 \\
Cotton income share of total income (\%) & $\mathbf{4 5 . 5}$ & 23.1 & .3 & 100 & 5190 \\
\hline
\end{tabular}

* Composed of cotton and other crops (mainly cereal) incomes.

Source: Sodecoton's surveys and author's calculations.

Table 8 shows that the share of cotton income represents, in average, about half (more precisely $45.5 \%$ ) of the whole seasonal income of cotton farmers. We thus fix average non-cotton income to the average cotton income of our sample.

It however can be assumed that cotton income and other incomes (mainly coming from other crops) are correlated. Even if each crop has its own specific growing period, a good rainy season for cotton is probably also good for other crops. The same reasoning can be applied to other shocks (e.g. locust invasions). As a robustness check (not shown here), we tested on-farm income as increasing in function of cotton income, by estimating the relation between both variables on the same surveys, but it did not modify the results significantly. 


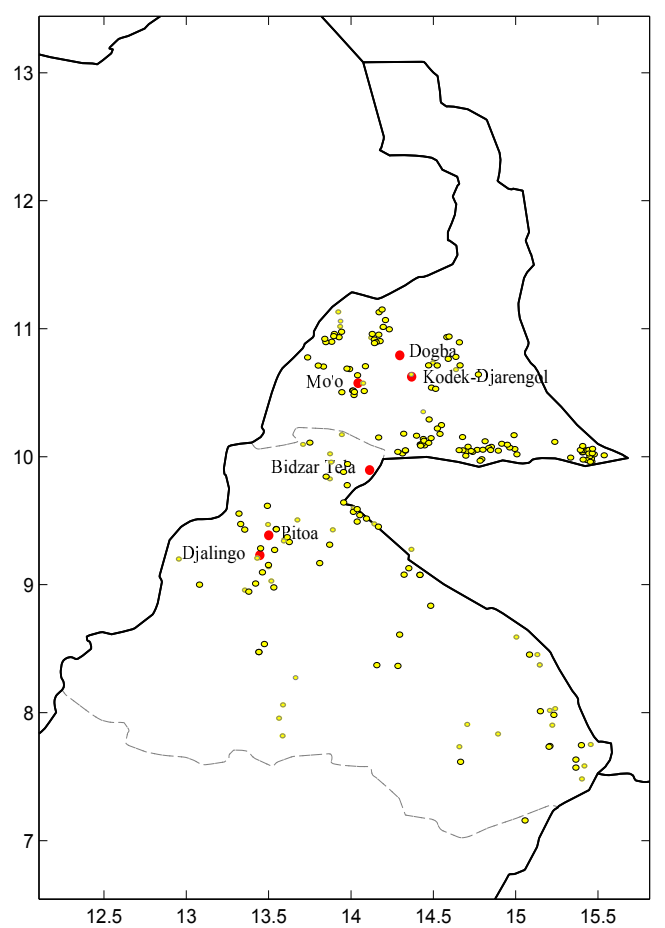

Figure 5: Villages in which lotteries were implemented (6 red dots), and Sodecoton's income surveys location (small yellow dots). 


\section{B Additional indices tested}

\section{B.1 Growing period and growing phases schedule}

We first consider the cumulative rainfall over the growing period. We then consider a refinement of the cumulative rainfall, by bounding daily rainfall at $30 \mathrm{~mm}$, corresponding to water that is not used by the crop due to excessive runoff (Baron et al., 2005).

As mentioned in section 3.2, we showed the results for indices on a growing season computed on an observed (obs) sowing date. However we compared those results to the ones of indices using a simulated sowing date, that were systematically found to be lower. We indeed also simulate a sowing date following a rainfall calculated criterion of the onset of the rainfall season, defined by Sivakumar (1988) and adapted to cotton, since cotton is sowed later than cereal crops in the Sudano-sahelian zone. It is based on the timing of first rainfalls daily occurrence and validated on the same zone by Bella-Medjo et al. (2009) and Sultan et al. (2010). We tested whether observing the sowing date could be useful to weather insurance compared to using a simulated sowing date. Indeed, simulated sowing date performed well for the same type of insurance contract in the case of millet in Niger (Leblois et al., 2011). We compared the two growing period schedules, and since we always found the observed one to perform better it is the only one discussed in the article.

We also try to distinguish different growing phases of the cotton crop. Cutting-in growing phases allows to determine a specific trigger for indemnifications in each growing phase. We do that by defining emergence, which occurs when reaching an accumulation of $15 \mathrm{~mm}$ of rain and 35 growing degree days (GDD) ${ }^{12}$ after the sowing date. We then set the length of each of the 5 growing phases following emergence only according to the accumulation of GDD, as defined by Crétenet and Dessauw (2006) and Freeland et al. (2006). The end of each growing phases is triggered by the following thresholds of degree days accumulation after emergence: first square (400), first flower (850), first open boll (1350) and harvest (1600). The first phase begins with emergence and ends with the first square, the second ends with the first flower. The first and second phases are the vegetative phases, the third phase is the flowering phase (reproductive phase), the fourth

\footnotetext{
${ }^{12}$ Calculated upon a base temperature of $13^{\circ} \mathrm{C}$.
} 
is the opening of the bolls, the fifth is the maturation phase that ends with harvest.

The use of different cultivars, adapted to the specificity of the climate (with much shorter growing cycle in the drier areas) requires to make a distinction different seasonal schedule across time and space.

For instance, recently, the IRMA D 742 and BLT-PF cultivars were replaced in 2007 by the L 484 cultivar in the Extreme North and IRMA A 1239 by the L 457 in 2008 in the North province. We simulated dates of harvest and critical growing phases ${ }^{13}$ using Dessauw and Hau (2002) and Levrat (2010). The beginning and end of each phase were constraint to fit each cultivar's growing cycle, table 9 in Appendix B.1 review the schedule of critical growing phases for each cultivar.

The total need is 1600 GDD, corresponding to about an average of 120 days in the considered producing zone, the length of the cropping season thus seem to be a limiting factor, especially in the upper zones (figure 2) given that an average of 150 is needed for regular cotton cultivars, Crétenet and Dessauw (2006).

Table 9: Cotton cultivars average spatial and temporal allocation

\begin{tabular}{lccc}
\hline $\begin{array}{c}\text { Cultivars } \\
\text { (by province) }\end{array}$ & $\begin{array}{c}1^{\text {st }} \text { flower date } \\
\text { (Days after emergence) }\end{array}$ & $\begin{array}{c}1^{\text {st }} \text { boll date } \\
\text { (Days after emergence) }\end{array}$ & Period of use \\
\hline Allen commun & 61 & 114 & untill 1976 \\
$444-2$ & 59 & 111 & untill 1976 \\
Allen 333 & 61 & 114 & $1959-197 ?$ \\
BJA 592 & 61 & 111 & $1965-197 ?$ \\
IRCO 5028 & 53 & 102 & untill 1987 \\
IRMA 1243 & 52 & 101 & 1987 - 1998 \\
IRMA 1239 & 52 & 101 & $2000-2007$ \\
IRMA A 1239 & 52 & 104 & $2000-2007$ \\
L 457 & & & 2008 -onwards \\
\hline Extrême-Nord & 59 & 109 & until 1984 \\
\hline IRMA L 142-9 & 55 & 115 & 1985 - 1991 \\
IRMA 96+97 & 51 & 99 & 2000 - 2006 \\
IRMA BLT & 56 & 116 & $2003-2006$ \\
IRMA BLT-PF & 51 & 95 & 2007 - onwards \\
IRMA D 742 & 51 & 105 & \\
IRMA L 484 & & & \\
\hline \hline
\end{tabular}

Sources: Dessauw (2008) and Levrat (2010).

\footnotetext{
13 See figure 6 in Appendix B.1 for the spatial distribution of cultivars.
} 


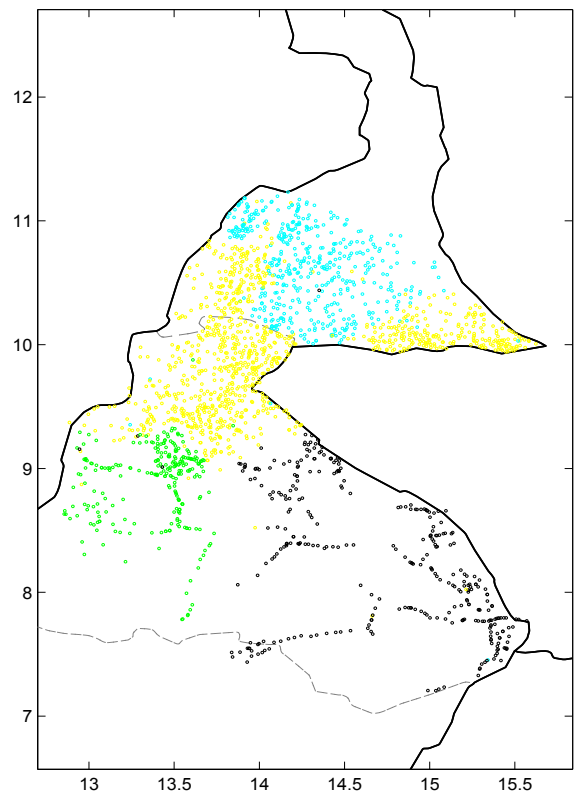

Figure 6: Spatial repartition of cultivars in 2010, dots are representing producers groups buying seeds, IRMA 1239 in black, IRMA A 1239 in green, IRMA BLT-PF in yellow and IRMA D742 in cyan. 


\section{B.2 Remote sensing indicators}

There is a cost in terms of transparency to use a complex vegetation index, such as NDVI, that is not directly understandable for smallholders. There is thus a trade-off to be made between delays (minimized when using near real-time products), transparency and basis risk. In a similar study in Mali (De Bock et al., 2010) vegetation index is found to be more precise than rainfall indices following a criterion of basis risk (defined as the correlation between yield and the index).

We used the bi-monthly satellite imagery (above-mentioned NDVI) during the growing season and considered annual series from the beginning of April to the end of October. We standardized the series, for dropping topographic and soil specificities, following Hayes and Decker (1996) and Maselli et al. (1993) in the case of the Sahel. There are 2 major ways of using NDVI: one can alternatively consider the maximum value or the sum of the periodical observation of the indicator (that is already a sum of hourly or daily data) for a given period (say the GS). As an example Meroni and Brown (2012) proxied biomass production by computing an integral of remote sensing indicators (in that particular case: FAPAR) during the growing period. Alternatively considering the maximum over the period is also possible since biomass (and thus dry weight) is not growing linearly with photosynthesis activity during the cropping season, but grows more rapidly when NDVI is high. McLaurin and Turvey (2012) for instance considers, in the case of index insurance, that the maximum represents the best vegetal cover attained during the GS and will better proxy yields. We thus tested indices using both methods and also considered all bi-monthly observations of standardized NDVI during the cotton cropping season.

\section{In-sample contract parameter calibration}


Table 10: Indemnification rate in in-sample calibrations (CRRA), among different rainfall zones, from 1991 to 2004.

\begin{tabular}{|c|c|c|c|}
\hline & $\rho=1$ & $\rho=2$ & $\rho=3$ \\
\hline \multicolumn{4}{|l|}{ First rainfall zone } \\
\hline AYII & $14.29 \%$ & $25.00 \%$ & $25.00 \%$ \\
\hline Length $_{\text {obs }}$ after sowing & $7.32 \%$ & $24.39 \%$ & $24.39 \%$ \\
\hline Sowing date ${ }_{o b s}$ & $.00 \%$ & $21.95 \%$ & $21.95 \%$ \\
\hline \multicolumn{4}{|l|}{ Second rainfall zone } \\
\hline AYII & $11.25 \%$ & $25.00 \%$ & $25.00 \%$ \\
\hline Length $_{\text {obs }}$ after sowing & $.00 \%$ & $12.20 \%$ & $24.39 \%$ \\
\hline Sowing date ${ }_{o b s}$ & $.00 \%$ & $24.39 \%$ & $24.39 \%$ \\
\hline \multicolumn{4}{|l|}{ Third rainfall zone } \\
\hline AYII & $17.65 \%$ & $22.35 \%$ & $24.71 \%$ \\
\hline Length $_{\text {obs }}$ after sowing & $.00 \%$ & $.00 \%$ & $4.08 \%$ \\
\hline Sowing date ${ }_{o b s}$ & $.00 \%$ & $.00 \%$ & $.00 \%$ \\
\hline \multicolumn{4}{|l|}{ Fourth rainfall zone } \\
\hline AYII & $17.60 \%$ & $24.80 \%$ & $24.80 \%$ \\
\hline Length $_{\text {obs }}$ after sowing & $.00 \%$ & $.00 \%$ & $.00 \%$ \\
\hline Sowing date ${ }_{o b s}$ & $.00 \%$ & $.00 \%$ & $.00 \%$ \\
\hline \multicolumn{4}{|l|}{ Fifth rainfall zone } \\
\hline AYII & $3.81 \%$ & $24.76 \%$ & $24.76 \%$ \\
\hline Length $_{\text {obs }}$ after sowing & $4.26 \%$ & $14.89 \%$ & $14.89 \%$ \\
\hline Sowing date ${ }_{o b s}$ & $4.26 \%$ & $12.77 \%$ & $12.77 \%$ \\
\hline
\end{tabular}

Table 11: Slope related parameter $(\lambda)$ in in-sample calibrations (CRRA), among different rainfall zones, from 1991 to 2004.

\begin{tabular}{|c|c|c|c|}
\hline & $\rho=1$ & $\rho=2$ & $\rho=3$ \\
\hline \multicolumn{4}{|l|}{ First rainfall zone } \\
\hline AYII & $64.29 \%$ & $64.29 \%$ & $64.29 \%$ \\
\hline Length $_{\text {obs }}$ after sowing & $100.00 \%$ & $100.00 \%$ & $100.00 \%$ \\
\hline Sowing date ${ }_{o b s}$ & $.00 \%$ & $7.14 \%$ & $64.29 \%$ \\
\hline \multicolumn{4}{|l|}{ Second rainfall zone } \\
\hline AYII & $100.00 \%$ & $100.00 \%$ & $100.00 \%$ \\
\hline Length $_{o b s}$ after sowing & $.00 \%$ & $100.00 \%$ & $92.86 \%$ \\
\hline Sowing date ${ }_{o b s}$ & $.00 \%$ & $57.14 \%$ & $57.14 \%$ \\
\hline \multicolumn{4}{|l|}{ Third rainfall zone } \\
\hline AYII & $14.29 \%$ & $92.86 \%$ & $92.86 \%$ \\
\hline Length $_{o b s}$ after sowing & $.00 \%$ & $.00 \%$ & $100.00 \%$ \\
\hline Sowing date ${ }_{o b s}$ & $.00 \%$ & $.00 \%$ & $.00 \%$ \\
\hline \multicolumn{4}{|l|}{ Fourth rainfall zone } \\
\hline AYII & $92.86 \%$ & $92.86 \%$ & $92.86 \%$ \\
\hline Length $_{o b s}$ after sowing & $.00 \%$ & $.00 \%$ & $.00 \%$ \\
\hline Sowing date ${ }_{o b s}$ & $.00 \%$ & $.00 \%$ & $.00 \%$ \\
\hline \multicolumn{4}{|l|}{ Fifth rainfall zone } \\
\hline AYII & $71.43 \%$ & $100.00 \%$ & $100.00 \%$ \\
\hline Length $_{\text {obs }}$ after sowing & $100.00 \%$ & $14.29 \%$ & $50.00 \%$ \\
\hline Sowing date ${ }_{o b s}$ & $7.14 \%$ & $.00 \%$ & $42.86 \%$ \\
\hline
\end{tabular}


Table 12: Maximum indemnification ( $M$, in CFA francs) in in-sample calibrations (CRRA), among different rainfall zones, from 1991 to 2004.

\begin{tabular}{|c|c|c|c|}
\hline & $\rho=1$ & $\rho=2$ & $\rho=3$ \\
\hline \multicolumn{4}{|l|}{ First rainfall zone } \\
\hline AYII & 74905 & 84268 & 93631 \\
\hline Length $_{o b s}$ after sowing & 22609 & 27131 & 31653 \\
\hline Sowing date ${ }_{o b s}$ & 0 & 76872 & 85915 \\
\hline \multicolumn{4}{|l|}{ Second rainfall zone } \\
\hline AYII & 22002 & 29336 & 33003 \\
\hline Length $_{o b s}$ after sowing & 0 & 19453 & 19453 \\
\hline Sowing date ${ }_{o b s}$ & 0 & 19453 & 23344 \\
\hline \multicolumn{4}{|l|}{ Third rainfall zone } \\
\hline AYII & 129991 & 39997 & 44997 \\
\hline Length $_{o b s}$ after sowing & 0 & 0 & 14530 \\
\hline Sowing date ${ }_{o b s}$ & 0 & 0 & 0 \\
\hline \multicolumn{4}{|l|}{ Fourth rainfall zone } \\
\hline AYII & 35852 & 46095 & 51216 \\
\hline Length $_{o b s}$ after sowing & 0 & 0 & 0 \\
\hline Sowing date ${ }_{o b s}$ & 0 & 0 & 10087 \\
\hline \multicolumn{4}{|l|}{ Fifth rainfall zone } \\
\hline AYII & 47279 & 33095 & 37823 \\
\hline Length $_{o b s}$ after sowing & 39961 & 154848 & 94907 \\
\hline Sowing date ${ }_{o b s}$ & 109892 & 84916 & 54946 \\
\hline
\end{tabular}

\section{Robustness to the objective function choice: re- sults with CARA}

Table 13: CEI gain (CARA) of index insurances relative to AYII absolute gain from 1991 to 2004 .

\begin{tabular}{lccc}
\hline \hline & $\psi=1 / W$ & $\psi=2 / W$ & $\psi=3 / W$ \\
\hline AYII CEI gain & $.40 \%$ & $1.16 \%$ & $1.88 \%$ \\
\hline CEI gains relative to AYII & & & \\
Length $_{\text {obs }}$ after sowing & $\mathbf{3 2 . 0 4} \%$ & $\mathbf{3 6 . 7 9} \%$ & $\mathbf{3 9 . 9 5} \%$ \\
Sowing date $_{\text {obs }}$ & $\mathbf{4 6 . 4 3} \%$ & $\mathbf{4 9 . 8 1} \%$ & $\mathbf{5 2 . 4 9} \%$ \\
\hline \hline
\end{tabular}

We display in bold insurance contract simulations that reach at least $25 \%$ of the AYII gain, i.e. a basis risk below $75 \%$. 
Table 14: In-sample and out-of-sample* estimated CEI gain (CARA) of index insurances relative to AYII absolute gain, among different rainfall zones, from 1991 to 2004.

\begin{tabular}{|c|c|c|c|}
\hline & $\psi=1 / W$ & $\psi=2 / W$ & $\psi=3 / W$ \\
\hline \multicolumn{4}{|c|}{ First rainfall zone } \\
\hline \multirow[t]{2}{*}{ AYII CEI gain } & $.11 \%$ & $.56 \%$ & $1.09 \%$ \\
\hline & $.10 \%$ & $.57 \%$ & $1.10 \%$ \\
\hline \multirow[t]{2}{*}{ Length $_{\text {obs }}$ after sowing } & $0 \%$ & $19.66 \%$ & $30.32 \%$ \\
\hline & $-47.22 \%$ & $-23.25 \%$ & $1.61 \%$ \\
\hline \multirow[t]{2}{*}{ Sowing date ${ }_{o b s}$} & $0 \%$ & $33.89 \%$ & $42.29 \%$ \\
\hline & $-15.84 \%$ & $32.68 \%$ & $43.58 \%$ \\
\hline \multicolumn{4}{|c|}{ Second rainfall zone } \\
\hline \multirow[t]{2}{*}{ AYII CEI gain } & $0 \%$ & $.19 \%$ & $.48 \%$ \\
\hline & $0 \%$ & $.17 \%$ & $.44 \%$ \\
\hline \multirow[t]{2}{*}{ Length $_{\text {obs }}$ after sowing } & $0 \%$ & $18.27 \%$ & $25.36 \%$ \\
\hline & $0 \%$ & $9.20 \%$ & $9.08 \%$ \\
\hline \multirow[t]{2}{*}{ Sowing date ${ }_{o b s}$} & $0 \%$ & $39.23 \%$ & $\mathbf{5 5 . 5 2} \%$ \\
\hline & $0 \%$ & $14.52 \%$ & $-56.34 \%$ \\
\hline \multicolumn{4}{|c|}{ Third rainfall zone } \\
\hline \multirow[t]{2}{*}{ AYII CEI gain } & $.05 \%$ & $.38 \%$ & $.79 \%$ \\
\hline & $.04 \%$ & $.22 \%$ & $.55 \%$ \\
\hline \multirow[t]{2}{*}{ Length $_{\text {obs }}$ after sowing } & $0 \%$ & $0 \%$ & $1.17 \%$ \\
\hline & $0 \%$ & $-223.85 \%$ & $-117.81 \%$ \\
\hline \multirow[t]{2}{*}{ Sowing date ${ }_{o b s}$} & $0 \%$ & $0 \%$ & $0 \%$ \\
\hline & $1748.96 \%$ & $-357.76 \%$ & $-158.65 \%$ \\
\hline \multicolumn{4}{|c|}{ Fourth rainfall zone } \\
\hline \multirow[t]{2}{*}{ AYII CEI gain } & $.08 \%$ & $.51 \%$ & $1 \%$ \\
\hline & $.07 \%$ & $.49 \%$ & $.98 \%$ \\
\hline \multirow[t]{2}{*}{ Length $_{\text {obs }}$ after sowing } & $0 \%$ & $0 \%$ & $0 \%$ \\
\hline & $0 \%$ & $0 \%$ & $0 \%$ \\
\hline \multirow[t]{2}{*}{ Sowing date $o b s$} & $0 \%$ & $0 \%$ & $0 \%$ \\
\hline & $0 \%$ & $0 \%$ & $0 \%$ \\
\hline \multicolumn{4}{|c|}{ Fifth rainfall zone sample } \\
\hline \multirow[t]{2}{*}{ AYII CEI gain } & $.04 \%$ & $.30 \%$ & $.65 \%$ \\
\hline & $.10 \%$ & $.19 \%$ & $.50 \%$ \\
\hline \multirow[t]{2}{*}{ Length $_{\text {obs }}$ after sowing } & $55.11 \%$ & $45.03 \%$ & $44.03 \%$ \\
\hline & $66.24 \%$ & $28.24 \%$ & $43.22 \%$ \\
\hline \multirow[t]{2}{*}{ Sowing date ${ }_{o b s}$} & $66.54 \%$ & $48.45 \%$ & $45.75 \%$ \\
\hline & $44.18 \%$ & $92.74 \%$ & $68.33 \%$ \\
\hline
\end{tabular}

* Leave-one-out estimations are displayed in italic.

We display in bold insurance contract simulations that reach at least $25 \%$, i.e. a basis risk below $75 \%$. 


\section{E Homogeneity of weather indices between periods}

Table 15: Student test of equality of mean inside and outside of the sub-period considered (1991-2004)

\begin{tabular}{|c|c|c|c|c|c|c|}
\hline Variable & Mean (1991-2010) & Mean $(>=2005)$ & Mean $(<2005)$ & $\mid$ Diff $\mid$ & $|\mathbf{t}|$ & $\operatorname{Pr}(|\mathbf{T}|>|\mathbf{t}|)$ \\
\hline Length $_{o b s}$ after sowing & 119.41 & 119.31 & 119.50 & 0.19 & 0.13 & 0.89 \\
\hline Sowing date ${ }_{o b s}$ & 181.99 & 181.20 & 180.50 & 1.48 & 1.38 & 0.17 \\
\hline
\end{tabular}

${ }^{*} p<.1,{ }^{* *} p<.05,{ }^{* * *} p<.01$

Generally indices were not significantly different in the two period before and after 2004, according to the student test (cf. Table 15), except for the bounded cumulative rainfall that was $40 \mathrm{~mm}$ higher in the second period.

Table 16: Chow test of equality of coefficients in linear time trends regressions inside and outside of the sub-period considered (1991-2004)

\begin{tabular}{|c|c|c|}
\hline Variable & Chow stat. (Fisher) & $\operatorname{Pr}$ (equal. coeff.) \\
\hline Length $_{\text {obs }}$ after sowing & 11.61 & 0.99 \\
\hline Sowing date ${ }_{o b s}$ & 9.54 & 0.99 \\
\hline
\end{tabular}

Table 16 shows that there is no significant rupture in the trend before and after 2004, according to the chow test. Table 15 and 16 makes us confident about the absence of trends and the applicability of the results of the period studied on the next one (after 2004).

\section{F Cotton income and observed sowing date}



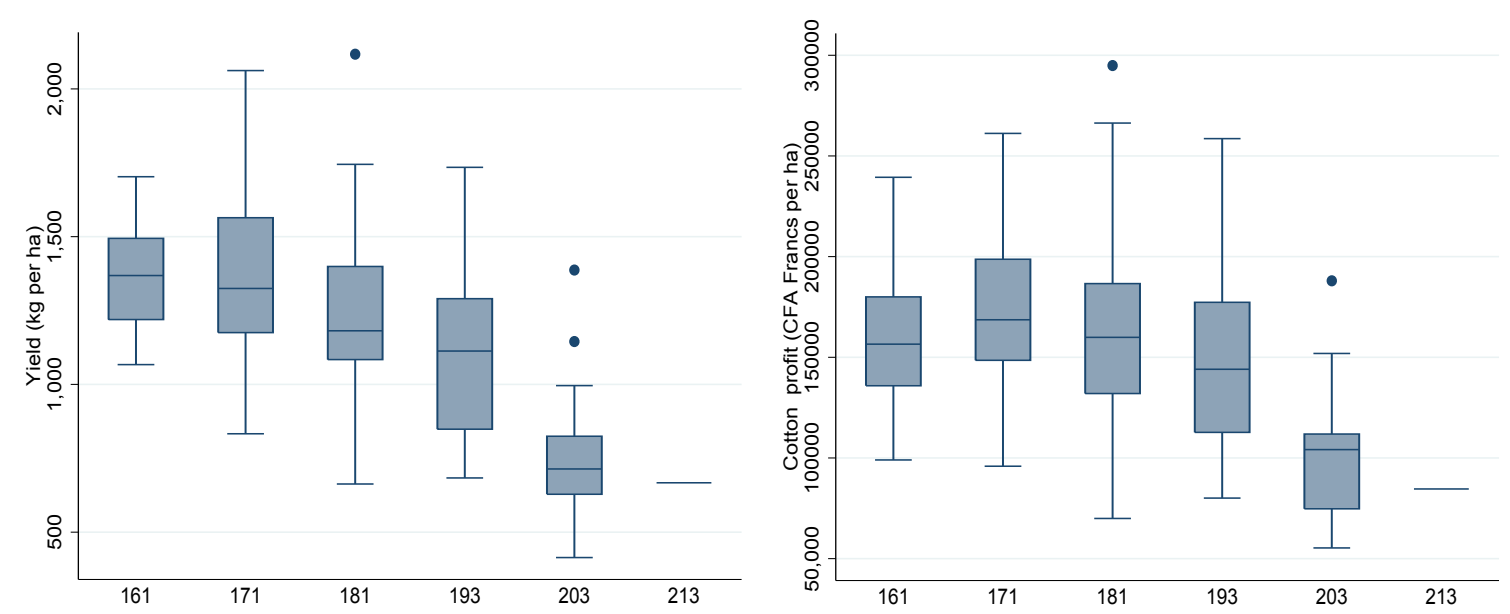

Figure 7: Box plot of cotton yield and profit (1991-2004), depending on observed sowing date expressed in calendar days after the first of January.

We show in Figure 7 the relation between yield and cotton profit, depending on the sowing date, observed every 10 day from the 10 of June to the first of August. The negative relation with yields, holds with cotton profits. 